\title{
Selective Flower Removal Increases Cranberry Fruit Set
}

\author{
Brian A. Birrenkott ${ }^{1}$ and Elden J. Stang ${ }^{2}$ \\ Department of Horticulture, University of Wisconsin-Madison, Madison, \\ WI 53706
}

\begin{abstract}
Additional index words. Vaccinium macrocarpon, pollination, intraplant competition, thinning
\end{abstract}

\begin{abstract}
Selective flower removal was used in 1987 and 1988 to evaluate intraplant competition or inhibition within flowering uprights of 'Searles' cranberry (Vaccinium macrocarpon Ait.). The lowest two flowers were removed from uprights at various stages of plant development in 1987. With one or both of the two earliest, i.e., lowest, flowers developing 'into fruit, $25 \%$ of the remaining flowers matured into fruit. Removal of the earliest two flowers at preblossom or late blossom resulted in $\approx 46 \%$ fruit set for the remaining flowers. Slightly fewer upper flowers set $(36 \%)$ when the earliest flowers and fruit were removed at early fruit development. In 1988, the lowest two flowers were removed at preblossom and natural insect pollination was supplemented by hand pollination. Hand-pollinated (upper) flowers set $58 \%$ when the lowest two flowers were removed, compared to $17 \%$ for the unthinned control. Yield and fruit numbers were lowered slightly as a result of flower thinning in both years. A significant amount of variation in fruit production was explained by the number of flowering uprights per unit of production area in both years.
\end{abstract}

The North American cranberry of commerce is a low-growing, broadleaf evergreen plant. Production areas consist of soil beds covered by vining runners. Short vertical stems called uprights develop from lateral buds on the runners. The flowers undergo anthesis acropetally on uprights. Each upright typically produces three to five flowers, often during three to' four weeks.

Inadequate" fruit set limits cranberry productivity (Eaton and Kyte, 1978; Eaton et

Received for publication 21 July 1989. Research supported in part by the College of Agricultural and Life Sciences, the Graduate School, Univ. of Wisconsin-Madison, and the Wisconsin cranberry industry under the auspices of the Wisconsin Cranberry Board, Inc. We thank DuBay Cranberries, Inc., Junction City, Wis., for their generosity in providing facilities and plantings used in this research. The cost of publishing this paper was defrayed in part by the payment of page charges. Under postal regulations, this paper therefore must be hereby marked advertisement solely to indicate this fact.

${ }^{1}$ Formerly, Graduate Research Assistant. Current address: O.M. Scott and Sons Co., Dwight G. Scott Research Center, 14310 Scottslawn Road, Marysville, $\mathrm{OH} 43041$.

${ }^{2}$ Professor. al., 1983). Normal fruit set in cranberry ranges from $30 \%$ to $40 \%$ (Bain, 1946; Bergman, 1950). Baumann and Eaton (1986) concluded that competition occurs between the berries on an upright, the lower flowers being more likely to develop into fruit. Fruit developing in the lower flower positions on a cranberry upright suppress fruit development by the remaining upper flowers, resulting in a temporal decline in fruit set (Birrenkott and Stang, 1989). Applications of a Ca-B formulation have been shown to increase cranberry fruit production, possibly through enhanced pollen germination (DeMoranville and Deubert, 1987). Gibberellins have increased cranberry fruit set and yield, although resulting fruit were small and parthenocarpic (Devlin and DeMoranville, 1967; Stang and Birrenkott, 1989).

This research was designed to more completely evaluate the competition within uprights by selectively removing the lowest two flowers at different stages of development or with supplemental hand pollination. Fruit set was subsequently determined for the remaining (upper) flowers.

In 1987, the lowest, i.e., earliest, two flowers (positions 1 and 2) were removed from uprights at the following stages of plant development: 1) preblossom- 15 June; 2) late blossom-24 June; 3) early fruit development -10 July; 4) no flower removal. Fruit set of remaining (upper) flowers was compared to unthinned uprights bearing fruit in positions 1, 2, or both. Only upper (position 3 and above) flowers and fruit were used as the source of data for the unthinned control. Uprights with fewer than three flowers were not used in fruit set determinations, but were included in yield and individual fruit weight. Forty locations were selected in a 'Searles' cranberry field at preblossom (11 June 1987) with 10 replicates per treatment in a completely randomized design, At each location, a PVC ring $(10.2-\mathrm{cm}$ id. $\times 1.8-\mathrm{cm}$ depth, $A=81 \mathrm{~cm}^{2}$ ) with support stake attached was inserted into the canopy to delineate areas for treatment and data collection. Thinned and unthinned uprights within rings were harvested on 26 Sept. 1987 for determination of fruit set, yield, and individual fruit weight.

In 1988, flowers in the lowest two floral positions on 'Searles' uprights were removed at preblossom, 21 June. Natural (insect) pollination was supplemented by hand pollinations at 2-day intervals throughout the blossoming period (27 June to 10 July. Treatments included: 1) flower removal plus hand pollination, 2) no removal plus hand pollination, and 3) no removal, natural insect pollination only. Thirty rings were inserted into the canopy on 21 June to delineate areas for treatment. Treatments were assigned to provide a completely randomized design with 10 replicates per treatment. Uprights were harvested on 20 Sept. for analysis of the same variables as' in 1987.

In both years, rings were placed $1.2 \mathrm{~m}$

Table 1. Yield and number of fruit in 'Searles' cranberry after removal of the lowest two flowers from uprights, 1987.

\begin{tabular}{lccccc}
\hline \hline & \multicolumn{4}{c}{$\begin{array}{c}\text { Fruit production/ring } \\
\left(81 \mathrm{~cm}^{2}\right)^{2}\end{array}$} \\
\cline { 2 - 6 } Stage of & \multicolumn{3}{c}{ Yield $(\mathrm{g})$} & \multicolumn{3}{c}{ No. fruit } \\
\cline { 2 - 6 } flower removal & Obs. & Adj. & Ohs. & Adj. \\
\hline Preblossom & 26 & 26 & ab & 21 & $20 \mathrm{ab}$ \\
Late blossom & 28 & 27 & ab & 22 & $21 \mathrm{ab}$ \\
Early fruit & 21 & 21 & $\mathrm{~b}$ & 16 & $16 \mathrm{~b}$ \\
No removal & 31 & 33 & $\mathrm{a}$ & 23 & $24 \mathrm{a}$ \\
\hline
\end{tabular}

${ }^{2}$ Adjusted mean $=$ observed mean $-\beta$ (mean no. flowering uprights/ring per treatment - mean no. flowering uprights/ring); $\beta=$ coefficient of covariate. Means within columns separated by Fisher's (protected) LSD, $P=0.05$. 
Table 2. Yield and number of fruit in 'Searles' cranberry after removal of the lowest two flowers at preblossom from uprights, with or without hand pollination of the remaining flowers, 1988.

\begin{tabular}{|c|c|c|c|c|c|}
\hline \multirow[b]{3}{*}{ Flowers removed } & \multirow[b]{3}{*}{ Hand-pollinated } & \multicolumn{4}{|c|}{$\begin{array}{l}\text { Fruit production/ring } \\
\left(81 \mathrm{~cm}^{2}\right)^{2}\end{array}$} \\
\hline & & \multicolumn{2}{|c|}{ Yield $(\mathrm{g})$} & \multicolumn{2}{|c|}{ No. fruit } \\
\hline & & Obs. & Adj. & Obs. & Adj. \\
\hline Yes & Yes & 17 & $20 \mathrm{a}$ & 19 & $21 \mathrm{a}$ \\
\hline No & Yes & 25 & $25 \mathrm{~b}$ & 25 & $25 \mathrm{~b}$ \\
\hline No & No & 22 & $20 \mathrm{a}$ & 23 & $21 \mathrm{a}$ \\
\hline
\end{tabular}

${ }^{2}$ Adjusted mean $=$ observed mean $-\beta$ (mean no. flowering uprights/ring per treatment - mean no. flowering uprights/ring); $B=$ coefficient of covariate. Means within columns separated by Fisher's (protected). LSD, $P=0.05$

Fruit set for upper flowers

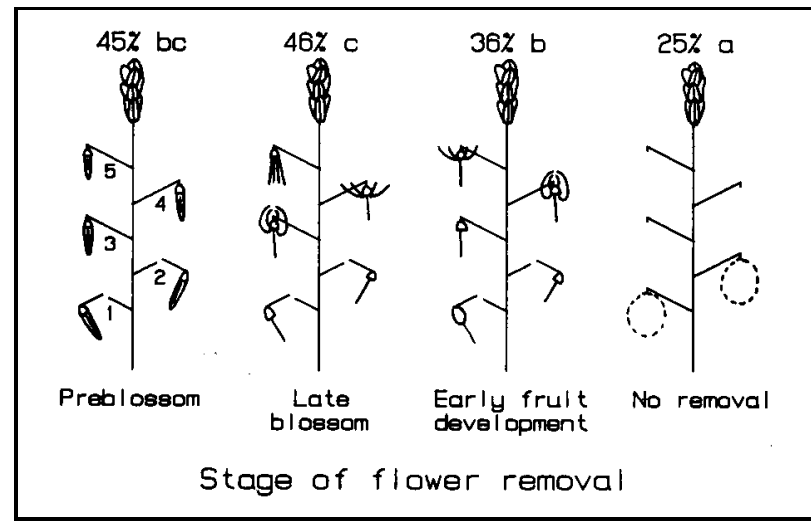

Fig. 1. Fruit set $(\%)$ for the. remaining flowers (positions 3 and higher) after the lowest two flowers (positions 1 and 2) were removed from upright shoots at various stages of development, 1987. Means with the same letter are not significantly different, Fisher's (protected) LSD, $P=0.05$. Sequential development shown includes new leaves at shoot tips, unopened pendulous flowers at preblossom, upper flowers at anthesis in the late blossom stage, and developing ovaries (fruit) at the lowest positions on the uprights.

Fruit set for upper flowers

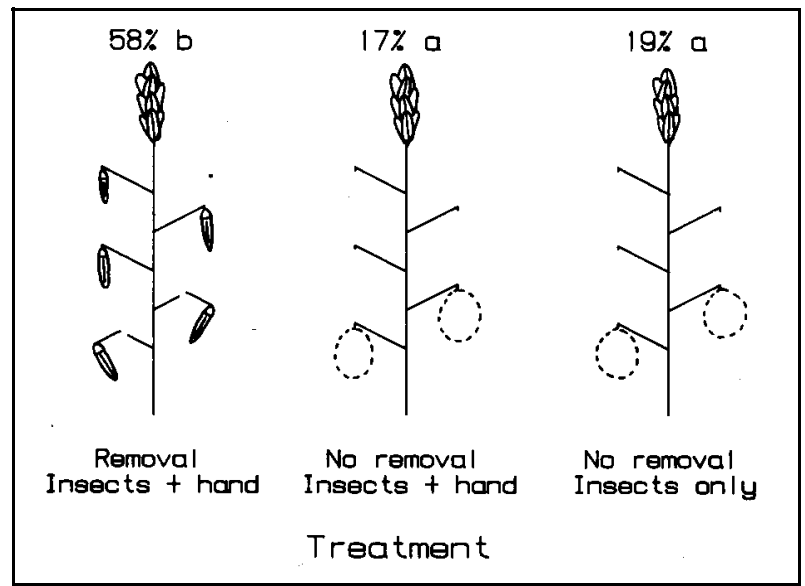

Fig. 2. Fruit set (\%) for the remaining flowers (positions 3 and higher) after the lowest two flowers (positions 1 and 2) were removed from uprights at preblossom, 1988. Natural insect pollination was supplemented by hand pollination in the treatments indicated. Means with the same letter are not significantly different, Fisher's (protected) LSD, $\mathrm{P}=0.05$.

apart in rows of the same spacing. If flowering uprights were not evident at the measured location, the ring was moved (usually $<30 \mathrm{~cm}$ ) to the nearest area containing flowering uprights. Conclusions regarding yield cannot therefore be directly extended to a larger area.

In each year, a pooled fruit set was calculated from the upper flowers of each ring and subjected to analysis of variance followed by Fisher's (protected) LSD, $P=0.05$.
Yield and number of fruit were analyzed using analysis of covariance in both years. The number of flowering uprights per ring was found to influence these variables and therefore was chosen as a covariate. The covariate was standardized by subtracting the average number of flowering uprights per ring. Observed means were adjusted according to the covariate. Statistical analysis and conclusions are based on adjusted values.

Fruit set for upper (later) flowers was in- creased when flowers were removed from the lowest two positions at all three dates in 1987 (Fig. 1). With fruit in position 1, 2, or both, $25 \%$ of the upper flowers developed into fruit. Removal of the lowest two flowers at preblossom and late blossom resulted in a near doubling of fruit set for the remaining flowers. Stimulation of fruit set was half as great when flowers were removed at early fruit development. This result was anticipated, since the number of fruit developed from the upper flowers was already determined before the lowest two flowers (ovaries) were removed in several of the uprights. Since early pollination was poor in 1987, control plots contained few uprights possessing fruit in position 1,2 , or both. Estimating fruit set based on insufficient numbers $(<25)$ of flowers can result in misleading information. A more precise estimate was calculated by using hand-pollinated uprights from an adjacent pollination experiment (Birrenkott and Stang, 1989) in which the majority of hand-pollinated uprights set fruit in the lower positions. With fruit in position 1 , 2 , or both, $18 \%$ of the upper flowers developed into fruit in the hand-pollinated uprights in this experiment.

Removal of the lowest two flowers at preblossom in 1988 increased fruit set for the remaining flowers (Fig. 2). Upper flowers pollinated by hand and insects set $58 \%$ when the lowest two flowers were removed. Similarly pollinated upper flowers of unthinned uprights bearing fruit in one or both of the lower positions set about one-third as much, and about the same as with insect pollination alone. In contrast to 1987, insect-pollinated control plots in 1988 contained a sufficient number of uprights bearing fruit in one or both of the lowest two positions. Therefore, more precise estimates of fruit set for upper flowers on uprights bearing fruit in these lower positions were obtained with both pollination treatments.

Yield and number of fruit responded similarly to flower removal in both years. In 1987, unthinned uprights produced $\approx 25 \%$ more fruit than those thinned at preblossom or late blossom (Table 1), but this difference in 'yield was not significant at $P=0.05$ in 1987. With supplemental hand pollination in 1988, removal of the lowest two flowers at preblossom reduced yield by $5 \mathrm{~g} /$ ring $(P=$ 0.01 ; Table 2). Lower yields as a result of flower removal were attributed to fewer fruits in both years (Tables 1 and 2), rather than differences in individual fruit weight (range 1.2 to $1.3 \mathrm{~g}, 1987 ; 0.9$ to $1.0 \mathrm{~g}, 1988$ ), i.e. the decline in yield parallels the decline in the number of fruit. Certain uprights, particularly those with three flowers before thinning, might have had the capability to develop additional fruit if the flowers were present, since some uprights with three to four fruit are observed in cranberry fields.

Cranberry fruit yield is determined largely by the number of flowering uprights per unit area (Eaton and McPherson, 1978). Including the number of flowering uprights per ring as a covariate removed a significant $(P<$ 0.01 ) amount of variation in fruit production in both years (data not shown).

With no flower removal, hand pollination 
increased yield from 20 to $25 \mathrm{~g}$ /ring in 1988 (Table 2). This yield difference is similar to that obtained from a pollination experiment in 1986 (Birrenkott and Stang, 1989) in which the average number of flowering uprights per ring was equal to that observed in 1988 (20 flowering uprights).

A recent study (Baumann and Eaton, 1986) also concluded that competition occurs between fruit on an upright, the lower positions being more likely to have fruit. In cranberry, intraplant competition or inhibition appears to suppress the first events in the fruit development phases, i.e., pollen tube growth and early seed development (Birrenkott and Stang, 1989). The ovary does not swell in the majority of flowers failing to develop fruit; however, initial ovary swelling was quite rapid in those flowers that ultimately developed (Chandler, 1952). The response of cranberry uprights as well as other plants to selective flower removal has two possible explanations: 1) developing fruit compete for limited resources, most likely photosynthates [for review, see Gifford and Evans (1981); Stephenson (1981)], or 2) early developing fruit (seeds) produce an inhibitory substance that subsequently causes later developing flowers and fruit to abort (Van Steveninck, 1959). The physiology involved in either has yet to be determined in cranberries.

\section{Literature Cited}

Bain, H.F. 1946. Blooming and fruiting habits of the cranberry in Wisconsin. Cranberries 10:11, 14.

Baumann, T.F. and G.W. Eaton. 1986. Competition among berries on the cranberry upright. J. Amer. Soc. Hort. Sci. 111:869-872.

Bergman, H.F. 1950. Cranberry flower and fruit production in Massachusetts. Cranberries 15:610.

Birrenkott, B.A. and E.J. Stang. 1989. Pollination and pollen tube growth in relation to cranberry fruit development. J. Amer. Soc. Hort. Sci. 114:733-737.

Chandler, F.B. 1952. Preliminary report on the development of cranberry fruit. Cranberries 17:67.

DeMoranville, C.J. and K.H. Deubert. 1987. Effect of calcium-boron and manganese-zinc formulations on fruit set of cranberries. J. Hort. Sci. 62:163-169.

Devlin, R.M. and I.E. DeMoranville. 1967. Influence of gibberellic acid and gibrel on fruit set and yield in Vaccinium macrocarpon cv. Early Black. Physiol. Plant. 20:587-592.

Eaton, G.W. and T.R. Kyte. 1978. Yield component analysis in the cranberry. J. Amer. Soc. Hort. Sci. 103:578-583.

Eaton, G.W. and E.A. McPherson. 1978. Morphological components of yield in cranberry. Hort. Res. 17:73-82.

Eaton, G. W., A.Y. Shawa, and P.A. Bowen. 1983. Productivity of individual cranberry uprights in Washington and British Columbia. Scientia Hort. 20:179-184.

Gifford, R.M. and L.T. Evans. 1981. Photosynthesis, carbon partitioning, and yield. Arm. Rev. Plant Physiol. 32:485-509.

Stang, E.J. and B.A. Birrenkott. 1989. Plant growth regulators alter fruit set and yield in cranberry. Acts Hort. 241:277-283.
Stephenson, A.G. 1981. Flower and fruit abortion: proximate causes and ultimate functions. Ann. Rev. Ecol. Syst. 12:253-279.
Van Steveninck, R.F.M. 1959. Abscission-accelerators in lupins (Lupinus luteus L.). Nature (London) 183:1246-1248.

Acts Hort. 241:277-283. 